\title{
CORTE INTERAMERICANA DE DIREITOS HUMANOS E SUA APROXIMAÇÃO COM O DIREITO INTERNACIONAL HUMANITÁRIO
}

\section{Resumo:}

$\mathrm{O}$ artigo explora a convergência entre o Direito Internacional dos Direitos Humanos e o Direito Internacional Humanitário na Corte Interamericana de Direitos Humanos. A análise parte da doutrina e do estudo de julgados do referido Tribunal nos casos de conflitos armados não internacionais. Com base nesta pesquisa, pretende-se demonstrar como a Corte se utiliza de um regime de Direito Internacional alheio ao Sistema Interamericano, sem se limitar ao princípio da lex speciallis, já adotado pela Corte Internacional de Justiça. Para tanto, a pesquisa levantou as decisões da Corte Interamericana onde o Direito Internacional Humanitário foi utilizado nos argumentos para fundamentação.

Palavras-chave: Sistema Interamericano de Direitos Humanos; Corte Interamericana de Direitos Humanos; Direito Internacional Humanitário; Conflitos Armados Internos.

\section{INTER-AMERICAN COURT OF HUMAN RIGHTS AND ITS APPROACH WITH INTERNATIONAL HUMANITARIAN LAW}

\begin{abstract}
:
This article aims to analyze the relation between the International Human Rights Law and International Humanitarian Law made by the Inter-American Court of Human Rights. The study examines the literature and the jurisprudence in cases regarding contexts of noninternational armed conflicts. The analysis address how the Inter-American Court has been using a regime of International Law, not limiting itself to the principle of lex speciallis, once adopted by the International Court of Justice. For this porpuse, the research raised the decisions of the Inter-American Court where International Humanitarian Law has been used in its arguments to support the sentence.
\end{abstract}

Key-words: Inter-American System of Human Rights; Inter-American Court of Human Rights; International Humanitarian Law; Non-Internaltional Armed Conflict.

\footnotetext{
* Advogada, Mestranda do Programa de Pós-Graduação em Direito da Universidade de São Paulo, voluntária da linha de pesquisa "Proteção Internacional de Direitos Humanos" na Clínica de Direitos Humanos da Amazônia. Endereço postal: R. Augusto Corrêa, 01 - Guamá, Belém - PA, 66075-110. Endereço eletrônico: carol.cazetta@gmail.com.

* Advogada, Mestranda do Programa de Pós-Graduação em Direito da Universidade Federal do Pará, voluntária da linha de pesquisa "Proteção Internacional de Direitos Humanos" na Clínica de Direitos Humanos da Amazônia. Endereço postal: R. Augusto Corrêa, 01 - Guamá, Belém - PA, 66075-110. Endereço eletrônico: mefonseca29@gmail.com.

" Doutora em Direito pela Universidade Federal do Pará, Professora do Programa de Pós-Graduação em Direito da Universidade Federal do Pará, Coordenadora da Clínica de Direitos Humanos da Amazônia. Endereço postal: R. Augusto Corrêa, 01 - Guamá, Belém - PA, 66075-110. Endereço eletrônico: cfterezo@ hotmail.com.
} 


\section{INTRODUÇÃO}

Devido ao contexto histórico de violações de Direitos Humanos e dos horrores vividos durante as guerras mundiais, passou-se a dar mais valor à proteção do indivíduo, sendo importante ressaltar que esta proteção não era apenas para situações de conflitos, mas também para os tempos de paz, isto é, em qualquer contexto no qual houvesse violação dos Direitos Humanos.

Considerando que o Direito Internacional tem como um dos seus objetivos salvaguardar o ser humano, observa-se sua fragmentação em três vertentes, que visam a tutela do indivíduo em contextos específicos, a saber: Direito Internacional dos Direitos Humanos (DIDH), Direito Internacional Humanitário (DIH) e Direito Internacional dos Refugiados (DIR) (CANÇADO TRINDADE et al, 2004).

No presente artigo será analisada a convergência entre o Direito Internacional dos Direitos Humanos e o Direito Internacional Humanitário, em especial, por meio da análise de sentenças e conceitos utilizados pela Corte Interamericana de Direitos Humanos, bem como por outros tribunais internacionais, como o Tribunal Europeu, a fim de demonstrar como esta complementaridade vem se apresentando na jurisprudência dos tribunais internacionais.

A análise da convergência entre DIDH e DIH é relevante para entender de que forma conceitos específicos do Direito Internacional Humanitário são analisados e utilizados pelo DIDH, como a criminalização do ato médico em cenários de conflito armado, a qual é proibida pelo DIH e, mais recentemente, pelo DIDH, principalmente pelo Tribunal Europeu de Direitos Humanos.

Identificou-se durante as pesquisas que o DIH apresenta normas de proteção mais amplas à vítima direta do caso, em comparação aos dispositivos normativos do DIDH existente no Sistema Interamericano de Direitos Humanos (SIDH), assim como para outras situações envolvendo, por exemplo, o direito à vida e grupos vulneráveis.

O presente artigo é resultado de pesquisa realizada em torno da aproximação entre esses dois regimes jurídicos, para verificar se é possível a convergência entre os dois ramos do direito internacional e como a Corte Interamericana de Direitos Humanos faz uso destes. Para isso, primeiramente foi realizado levantamento de leituras referentes ao Direito Internacional Público, priorizando as que analisavam ambos os ramos do direito em questão, como CANÇADO TRINDADE, EL KOUHENE, HENKAERTS e DOSWALD. 
Em seguida, tem-se a análise de documentos internacionais específicos sobre Direito Internacional Humanitário -- por exemplo as Convenções de Genebra -- bem como de casos analisados por outras cortes -- Corte Internacional de Justiça -- para enfim chegarmos a análise da Corte Interamericana.

A partir disso, foram escolhidos os casos que envolviam o contexto de conflito armado interno no referido Tribunal, desde o primeiro caso julgado pela Corte Interamericana em 1987 até 2020, para verificar se há convergência e se há, de fato, ampliação do corpus juris dos tratados internacionais, para além dos pertencentes ao Sistema Interamericano, o qual seria de sua competência, fazendo uso ainda de outros regimes que não próprios do DIDH. Por fim, com base nos casos analisados, verificou-se a repetição de alguns temas, os quais foram destacados no presente artigo.

\section{DIREITO INTERNACIONAL DOS DIREITOS HUMANOS E DIREITO INTERNACIONAL HUMANITÁRIO: UMA POSSÍVEL CONVERGÊNCIA}

As Guerras Mundiais, sobretudo os horrores vividos em decorrência no nazismo na Segunda Guerra, representaram um afastamento, uma ruptura com os Direitos Humanos. Como entende Hidaka (2002, p. 24-25), caso houvesse um efetivo sistema de proteção internacional dos Direitos Humanos capaz de responsabilizar os Estados pelas violações por eles cometidas, ou ocorridas em seus territórios, talvez o mundo não tivesse vivenciado os horrores das guerras em uma escala tão grande. Assim, têm-se o entendimento de que os Estados são responsáveis pelos atos que praticam e pelos atos ocorridos em seu território e que, como afirma Bilder, a comunidade internacional tem o direito e a responsabilidade de protestar, se um Estado não cumprir com suas obrigações (BILDER et al, 2006, p. 6).

O pós-guerra é marcado pela tentativa de deslegitimação da guerra ou, como afirmam Hathaway e Shapiro, a iniciativa para tornar a guerra ilegal ${ }^{1}$ e a cooperação internacional são características da mudança para a Nova Ordem Mundial, em que surgem organismos internacionais e agências especializadas para a regularização do Direito Internacional (HATHAWAY; SHAPIRO, 2017, pp. 340-343).

\footnotetext{
${ }^{1}$ Outlaw war.
} 
Diante desse contexto, observa-se que o surgimento do Direito Internacional dos Direitos Humanos emana do Direito Internacional e adquire autonomia na medida em que regula relações jurídicas específicas. Para Cançado Trindade, este ramo do Direito Internacional é entendido como o corpus juris de salvaguarda do ser humano, composto por normas, princípios e conceitos definidos em tratados, com o propósito de proteger o ser humano em todas e quaisquer circunstâncias, sobretudo em suas relações com o poder público (CANÇADO TRINDADE, 2007, p. 412).

Já o Direito Internacional Humanitário é um ramo do Direto Internacional, que visa a proteção do indivíduo em situações de conflito armado, com o intuito de diminuir o sofrimento causado pela guerra, ao proteger e assistir as vítimas. Assim, o DIH abrange as normas jus in bello, que são aquelas que se preocupam com as questões humanitárias dentro do conflito e que devem ser atendidas pelas partes conflitantes, pois não importam os motivos do conflito ou seus objetivos, mas, sim, a proteção do ser humano (ICRC).

Este ramo do Direito Internacional também foi influenciado pela Segunda Guerra e contava com o Direito de Haia e o Direito de Genebra. Contudo, o primeiro acabou sendo incorporado ao segundo. Assim, o DIH abrange as quatro Convenções de Genebra, aprovadas em 1949 e seus dois Protocolos Adicionais, aprovados em 1977 (CIJ, 2004).

Observa-se que ambas as vertentes possuem como objetivo comum a proteção do ser humano, diferindo apenas no contexto em que esta tutela ocorre. Como ressalta Cançado Trindade (2004), alguns documentos do Direito Internacional dos Direitos Humanos, como os Pactos Internacionais de Direitos Civis e Políticos e de Direitos Econômicos, Sociais e Culturais (1966) e a própria Convenção Americana de Direitos Humanos (1969) influenciaram o conteúdo dos Protocolos Adicionais de 1977, assim como o DIDH recebe a influência das Convenções de Genebra.

Pode-se, assim, afirmar que estas se complementam, pois, nem sempre a situação concreta e real vai permitir que se retrate precisamente o quadro descrito e tutelado por cada área, de forma que se possa definir com exatidão qual deverá ser utilizado em determinado contexto de violação de direito, existirão momentos em que ambos poderão ser aplicados, sem que isso signifique que deve ser feita uma opção entre eles. Isto é, a aplicação de normas do DIH não impede a convergência e aplicação das normas do DIDH (CorteIDH, 2004c, §112). 
É preciso que se entenda que o DIDH não é apenas o direito aplicável aos "tempos de paz”. Em situações em que não há conflitos é clara sua aplicação, mas também existirão momentos que ele será demandado para resolver questões que estão ocorrendo em um contexto de conflito armado, o qual seria tutelado pelo DIH. Contudo, o que se pretende com o presente artigo é demonstrar que esta separação não é necessária, visto que ambos os ramos do Direito Internacional podem ser aplicados de forma conjunta.

Antes de adentrar na questão da complementariedade, deve-se ressaltar que existem outros entendimentos controversos em relação à aplicação do DIDH e do DIH, por exemplo, mediante o princípio da lex speciallis, segundo o qual a norma que deve ser aplicada é a mais específica e não a mais geral, isto é, a norma que é mais explícita em detrimento daquela que é mais implícita (ONU, 2006, p. 409).

De acordo com o entendimento anterior da Corte Internacional de Justiça (CIJ) (1996, §25), em uma situação de conflito armado deve ser aplicado o princípio da lex speciallis, o que levaria a utilização do Direito Internacional Humanitário. Já em sua Opinião Consultiva mais recente sobre as consequências legais para a construção do muro nos territórios ocupados da Palestina (CIJ, 2004, §105-106), a Corte Internacional de Justiça mudou seu posicionamento trazendo três possibilidades em relação a lex speciallis: a primeira afirma que alguns direitos devem ser tratados à luz do DIH; a segunda diz que situações devem ser tratadas exclusivamente sob as normas de DIDH; e a terceira permite a utilização tanto do DIDH quanto do DIH. No caso dos territórios ocupados da Palestina, a CIJ empregou a terceira possibilidade.

Deste exemplo, é possível depreender que embora existam violações a direitos que são tutelados pelo Direito Internacional dos Direitos Humanos, podem existir momentos em que estas violações irão ocorrer em um contexto de conflito armado, que seria protegido pelo Direito Internacional Humanitário e, para que haja maior proteção do indivíduo, ambos devem ser utilizados.

Acerca deste entendimento, a CorteIDH já se pronunciou no caso Irmãs Serrano Cruz Vs. El Salvador (2004) que:

Durante um conflito armado interno ou internacional se encontra protegida tanto pelas normas de Direito Internacional dos Direitos Humanos quanto pelas normas de Direito Internacional Humanitário, motivo pelo qual há uma convergência de normas internacionais que amparam as pessoas que se encontram nesta situação (CorteIDH, 2004c, §112). 
Os conflitos armados não internacionais proporcionam maior compreensão desta convergência (EL KOUHENE, 1986), pois além de preverem a proteção dos Direitos Humanos em relação aos conflitos, preveem a proteção de direitos na relação do Estado com o indivíduo. Kleffner aponta que os dois ramos do direito - DIH e DIDH - se complementam mutuamente e aperfeiçoam, em graus a depender da situação analisada (KLEFFNER, 2021, p. 451).

Alguns autores, como Megret, afirmam ainda que em alguns casos o Direito Internacional dos Direitos Humanos pode apresentar uma resposta melhor e mais desenvolvida, como no que diz respeito a detenção legal (MEGRET, 2019, p. 172) Nesse sentido, é possível observar a complementariedade do DIDH e do DIH nestes casos.

\subsection{CONVERGÊNCIA NO ÂMBITO DOS DOCUMENTOS INTERNACIONAIS E NA JURISPRUDÊNCIA INTERNACIONAL}

A convergência entre os já citados ramos do Direito Internacional pode ser observada ainda pela interpretação de alguns dispositivos de documentos internacionais. A Convenção de Viena sobre os Direitos dos Tratados traz as regras de interpretação e em seu artigo 31.2.c afirma que devem ser consideradas as normas de Direito Internacional que sejam pertinentes a situação enfrentada pelas partes, isto é, se DIDH e DIH forem pertinentes para o contexto de violações, ambos deverão ser considerados.

Este entendimento corrobora com o que a Convenção Americana de Direitos Humanos (CADH) dispõe em seu artigo 29, que também trata da interpretação:

Nenhuma disposição desta Convenção pode ser interpretada no sentido de: limitar o gozo e exercício de qualquer direito ou liberdade que possam ser reconhecidos de acordo com as leis de qualquer dos Estados Partes ou de acordo com outra convenção em que seja parte um dos referidos Estados.

Com isso, dizer que a Corte Interamericana, por exemplo, não pode fazer uso do Direito Internacional Humanitário seria ir contra a Convenção, visto que a utilização deste é uma forma de ampliar a interpretação da própria $\mathrm{CADH}$, proporcionado assim maior proteção dos direitos aos indivíduos.

Além disso, o artigo 38 do Estatuto da Corte Internacional de Justiça afirma que ela utilizará as convenções internacionais gerais e especiais para auxiliar na sua decisão (ONU, 1945), ou seja, não é necessário que a CIJ opte por um dos ramos, desde que ambos sejam reconhecidos pelo Estado litigante. 
Para além do que dispõe os tratados internacionais, resta destacar alguns julgados que apontam também para uma convergência entre as duas áreas de Direito Internacional, de forma a rechaçar a teoria de aplicação da lex speciallis.

Em 2004, no caso De la Cruz Flores Vs. Peru, a CorteIDH utiliza a I Convenção de Genebra e seus Protocolos Adicionais como reforço argumentativo para tratar a respeito da assistência médica, pois a senhora De La Cruz Flores foi detida por ter supostamente prestado serviços médicos à membros do Sendero Luminoso, dispondo que "a título informativo, a Corte recorda que o artigo 18 da I Convenção de Genebra de 1949, afirma que ninguém pode ser maltratado ou condenado pelo fato de ter prestado assistência a feridos ou a enfermos" (CorteIDH, 2004a, §95).

Em 2014, no caso Margus Vs. Croácia, o Tribunal Europeu de Direitos Humanos (TEDH) utiliza os costumes de DIH como reforço argumentativo para resolver uma situação relacionada à anistia, citando também o Comitê Internacional da Cruz Vermelha e o Protocolo II adicional as Convenções de Genebra, ao afirmar que:

[...] os acusados são culpados por desrespeitar o artigo $3 \$ 1$ da Convenção de Genebra relativa a proteção de civis em tempos de guerra e o artigo 4 §§ 1 e 2 e o artigo 13 do Protocolo II de 8 de junho de 1977, enquanto defendiam o território contra-ataques da população sérvia rebelde e do 'Yugoslav People’s Army' [...] pela intenção de matar os civis sérvios. (TEDH, 2014, §23)

Deve-se registrar ainda julgados onde os Tribunais internacionais de Direitos Humanos embora não apliquem diretamente, fazem a interpretação devida do DIH enquanto fonte de Direito. Essa relutância na aplicação direta é criticada por Andrea Gioia que acredita que as Cortes preferem “ignorar” essa relação entre os dois ramos (GIOIA, 2011, p. 203).

Com efeito, em 2000, no caso Bácama Velasquez Vs. Guatemala, a CorteIDH afirma que, apesar de carecer de competência para declarar que um Estado é internacionalmente responsável pela violação de tratados internacionais que não a atribuíram tal competência, se pode observar que certos atos ou omissões que violam os Direitos Humanos, encontram-se proibidos não somente pelos tratados interamericanos, mas também para outros instrumentos internacionais de proteção, como as Convenções de Genebra. Neste caso, a Corte afirma ainda que "há efetivamente uma equivalência entre o conteúdo do artigo 3 comum as Convenções de Genebra e as disposições da Convenção Americana e de outros documentos internacionais acerca dos direitos humanos inderrogáveis” (CorteIDH, 2000a, §209) 
No caso Las Palmeras Vs. Colômbia de 2000, surge a discussão entre a aplicação e a interpretação do DIH pela Corte Interamericana, pois o Estado da Colômbia sustenta que o Tribunal não tem competência para aplicar o Direito Internacional Humanitário, somente a Convenção Americana. No entanto, a CorteIDH argumenta pela utilização de outros documentos internacionais de forma a auxiliá-la na interpretação da Convenção, fazendo referência do já comentado artigo 29 da $\mathrm{CADH}^{2}$ (CorteIDH, 2000b, §34). Da mesma forma, a CorteIDH o faz em 2015, no caso Cruz Sánchez e outros Vs. Peru, onde utiliza também o artigo 3 comum as Convenções de Genebra, para ampliar o conteúdo do artigo 4 da CADH e afirma que "é pertinente recorrer ao corpus iuris de DIH aplicável a fim de determinar o alcance das obrigações estatais no que concerne a garantia do direito à vida" (CorteIDH, 2015, §273).

Atribuindo reforço à complementariedade entre os dois regimes, em 2012, no caso Massacres de El Mozote e lugares próximos Vs. El Salvador, a CorteIDH se utiliza do DIH para definir o alcance da $\mathrm{CADH}$, afirmando que o Direito Internacional Humanitário poderia ser utilizado de forma complementar devido a sua especificidade (CorteIDH, 2012, §141).

Com relação ao TEDH, em 2008, no caso Korbely Vs. Hungria, a Corte Europeia interpreta diretamente o artigo 3, comum das quatro Convenções de Genebra, para definir se Korbely poderia ou não ser considerado combatente ${ }^{3}$ (TEDH, 2008, §94), uma definição utilizada pelo DIH. Já em 2014, no caso Hassan Vs. Reino Unido do TEDH, foi a primeira vez que um Estado pediu o afastamento das normas de DIDH para a aplicação exclusiva do DIH, o que não foi aceito. Entretanto, este caso permitiu que o Tribunal Europeu se pronunciasse no sentido de afirmar que "a Convenção Europeia não pode ser interpretada em um vácuo e deve, tanto quanto possível, ser interpretada em harmonia com outras normas de Direito Internacional de que faz parte” (TEDH, 2014, §77). Deste trecho da sentença entende-se que para o TEDH a Convenção Europeia deve ser interpretada à luz do DIH.

\footnotetext{
2 "Estado señaló que estaba de acuerdo con interpretar armónicamente la Convención con otros tratados, pero no admitió la aplicación del artículo 3 común como una norma infringida por Colombia en un caso individual. Tanto el artículo 25 como el 27.1 y 29.b), por su ubicación en el texto de la Convención, no pueden ser considerados como normas atributivas de competencia; son normas que establecen derechos y la última, es una norma de interpretación".

3 "The Court therefore is of the opinion that Tamás Kaszás did not fall within any of the categories of noncombatants protected by common Article 3. Consequently, no conviction for crimes against humanity could reasonably be based on this provision in the present case in the light of relevant international standards at the time."
} 


\section{A CORTE INTERAMERICANA DE DIREITOS HUMANOS E A PROTEÇÃO DO DIREITO INTERNACIONAL HUMANITÁRIO}

A utilização do Direito Humanitário pela Corte Interamericana não ocorre com o propósito de declarar violados artigos de documentos humanitários - por exemplo as Convenções de Genebra - porém, se dá como reforço argumentativo, de forma a complementar o entendimento da Corte acerca do contexto em que as violações ocorrem ou mesmo ainda ampliar o conteúdo dos dispositivos da $\mathrm{CADH}$, por meio de tratados de Direito Internacional Humanitário.

Como afirmado anteriormente, os casos envolvendo o DIH apresentam um contexto de conflito armado, portanto, é necessário observar que o discurso estatal que os envolve é de proteção da população civil e da segurança nacional. No entanto, a CorteIDH afirma que a prevenção e repressão do crime devem ocorrer dentro dos limites e conforme os procedimentos, que permitam preservar a segurança pública e o desenvolvimento dos Direitos Humanos daqueles que se submetem a sua jurisdição, de forma que o Estado não está exonerado de respeitar e garantir os direitos das pessoas estabelecidos na Convenção, independentemente do quão difícil é a situação do país (CorteIDH, 2016, §250).

Para isso, o Tribunal utiliza das normas e princípios do Direito Internacional Humanitário consuetudinário, os quais são norteadores para analisar se as violações alegadas podem ser aplicadas no caso específico. Dentre estes, encontram-se os princípios da distinção, proporcionalidade e precaução, tendo utilizado de forma expressa em casos recentes, como o caso Massacre de Santo Domingo Vs. Colômbia (CorteIDH, 2012a, §211).

Ademais, no levantamento jurisprudencial feito pela presente pesquisa, nos casos julgados pela CorteIDH em que o aborda o DIH, verificou-se que é ressaltado o caráter da vulnerabilidade que permeia o contexto, representado em algumas situações, assim como o deslocamento interno e internacional e a caracterização do direito à vida à luz das Convenções de Genebra.

Uma vez que estes pontos possuem características peculiares, o presente artigo enfrentará cada um de forma específica e sua aplicação pela Corte Interamericana de Direitos Humanos. 


\subsection{OS PRINCÍPIOS DA DISTINÇÃO, DA PRECAUÇÃO E DA PROPORCIONALIDADE DO DIREITO INTERNACIONAL HUMANITÁRIO}

A utilização destes três princípios decorre da importância de cada um deles, os quais estão elencados nas 4 Convenções de Genebra e são utilizados pelo Comitê Internacional da Cruz Vermelha para a esclarecer conceitos que são específicos de momentos de conflito armado.

O princípio da distinção aplica-se para os conflitos armados internos e internacionais, em que as partes devem distinguir entre os civis e combatentes, bem como entre objetivos e bens civis e objetivos e bens militares, para restringir os ataques apenas aos combatentes, aos bens e objetivos militares (HENKAERTS et al, 2007, p.3). Da mesma forma dispõe o parágrafo 2 do artigo 13 do Protocolo Adicional II às Convenções de Genebra, ao proibir o ataque aos civis e o artigo 3 comum às 4 Convenções, pois faz a distinção entre aqueles que estão em combate, os que tenham depostos as armas e os feridos. É importante ressaltar que a distinção terá como parâmetro apenas a atuação direta nas hostilidades (ICRC, 2010, Capítulo $1)$.

Além disso, o Guia para Interpretação de Pessoas em Combate Direto do Comitê Internacional da Cruz Vermelha (ICRC, 2010) aponta que deve ser analisada a limitação do dano provocado, a causalidade direta e o nexo beligerante. Ademais, o Guia indica o lapso temporal, em que o combatente pode vir a ser considerado desta forma em razão da atividade, portanto, há uma perda contínua da proteção que seria a ele concedida, caso participasse como civil.

A Corte Interamericana nunca se utilizou deste princípio para permitir a aplicação do termo "alvo legítimo de ataque" pelos Estados, ou seja, que esse conceito do Direito Internacional Humanitário, venha eximir os Estados da responsabilização das violações dos direitos tutelados pela CADH. Cita-se como exemplo o caso Myrna Mack Chang Vs. Guatemala (2003), em que o Estado da Guatemala foi condenado, pois se utilizou da justificativa de que a vítima era um "alvo legítimo de ataque militar", iniciando uma operação para realizar a execução da senhora Myrna Mack Chang.

Ainda no referido caso, a Corte entendeu que as atividades das forças militares deveriam seguir alguns critérios, dentre eles o respeito a todo momento pelos direitos fundamentais das pessoas, sujeitas ao controle das autoridades civis, não apenas do executivo, 
mas também de outros poderes públicos, bem como os trabalhos do serviço de inteligência deveriam ser rigorosos, em face das violações aos Direitos Humanos e ilícitos penais que possam ocorrer, tal qual no presente caso (CorteIDH, 2003, §284). Porém, a CorteIDH não se pronunciou acerca da possibilidade de um civil ou combatente vir a ser considerado como "alvo legítimo de ataque militar".

No que pese esse posicionamento da Corte, a Comissão Interamericana afirmou no caso Juan Carlos Abella Vs. Argentina que os combatentes individuais ou membros de grupos que atuam de forma direta no conflito podem vir a ser considerados alvos legítimos de ataque militar. Por isso, estes atores serão considerados extensões do ataque, perdendo os benefícios de proteção concedidos aos civis não combatentes (CIDH, 1997, §178). Porém, diante do caso apresentado a CIDH entendeu que, no momento da violação do direito à vida do senhor Juan Carlos Abella, a vítima estava em hors de combat, portanto, possuía os benefícios concedidos aos civis.

Para a análise do princípio da distinção em relação aos civis e combatentes, a CorteIDH (2015, §287) utilizou-se de um caso do Tribunal Europeu de Direitos Humanos, que determina dois critérios para análise: a previsibilidade e acessibilidade. O TEDH entendeu que deveria ser analisado se a conduta do suposto agente era suficiente para fundamentar e imputar o crime (acessibilidade) e se a conduta era um ato isolado ou se era parte de um conjunto de ações, uma política estatal contra os civis, ou ainda parte de ataques do Estado realizados de forma sistemática contra os cidadãos (TEDH, 2008, §§90 e 91).

No caso Cruz Sánchez e outros Vs. Peru, a Corte utilizou deste princípio - da distinção - para responsabilizar o Estado do Peru em relação a violação do direito à vida do senhor Cruz Sánchez e das demais vítimas, as quais foram detidas publicamente pelo Estado durante a retirada dos reféns da residência do Embaixador Japonês. Após a referida detenção, alegou-se que a morte como legítima, vez que o senhor Cruz Sánchez estava na condição de combatente. No entanto, a Corte entendeu que, em decorrência da detenção, a qual ocorreu de forma pública, o senhor Sánchez não representava perigo aos presentes, não podendo ser considerado mais como um combatente de forma direta das hostilidades, condenando o Estado do Peru (CorteIDH, 2015, §287).

Quanto ao princípio da proporcionalidade, o DIH proíbe que um ataque seja realizado se for possível, por prever mortos e feridos incidentais entre a população civil, bem 
como dano aos bens de caráter civil, os quais sejam excessivos em face da vantagem militar concreta direta e prevista (HENKAERTS, 2007, p.53). No entanto, a caracterização desta vantagem deve ser analisada caso a caso, mas não há um consenso hipotético do que seriam os danos excessivos. Por este motivo, são analisados os princípios de uso da força, o qual deve ser limitado ao indispensável para alcançar esta vantagem perseguida.

Ademais, a Corte elenca a proporcionalidade entre os critérios para o uso da força. No caso Nadege Dorzema Vs. República Dominicana, são estabelecidos três critérios de análise $^{4}$ : a legalidade (se é dirigido a um objetivo legítimo, ou se há a legislação), a absoluta necessidade (se todos os meios disponíveis, de acordo com as circunstâncias, foram utilizados) e a proporcionalidade (se apresentou alta resistência, se foram realizadas negociações ou adotadas medidas preventivas). Da mesma forma entendeu o Comitê Internacional da Cruz Vermelha em seu relatório sobre Violência e Uso da Força (CorteIDH, 2012c, §85) sobre os critérios que devem ser analisados.

Ainda sobre a utilização da força, a Corte faz uso dos Princípios Básicos do Uso da Força e de Armas de Fogo pelos funcionários responsáveis pela aplicação da lei (ONU, 1990), os quais apontam a permissão de utilização de armas de fogo desde que proporcional em face da gravidade do delito e do objetivo perseguido (princípios básicos 4 e 5), bem como em defesa própria ou de outras pessoas quando houver perigo iminente de morte ou lesões graves - princípio básico 9 (ONU, 1990).

Ao analisar os fatos do caso Massacre de Santo Domingo Vs. Colômbia de 2012, verifica-se que o Tribunal aplicou este princípio, por entender que a utilização de munição Cluster, a qual é proibida no âmbito internacional em face do seu poder destrutivo, (ONU, 2010) afetou a população de Santo Domingo, embora o objetivo fosse enfraquecer os grupos guerrilheiros que se encontravam na região. Por estes motivos, a Corte teria que analisar se os feridos e mortos foram resultado de excesso ou não no contexto apresentado, o que a Corte entende que não ocorreu (CorteIDH, 2012a, §215).

\footnotetext{
4 “(...) ésta debe realizarse en armonía con los principios de legalidad, absoluta necesidad y proporcionalidad: i. Legalidad: el uso de la fuerza debe estar dirigido a lograr un objetivo legítimo (...). ii. Absoluta necesidad: es preciso verificar si existen otros medios disponibles para tutelar la vida e integridad de la persona o situación que pretende proteger, de conformidad con las circunstancias del caso (...) iii. Proporcionalidad: el nivel de fuerza utilizado debe ser acorde con el nivel de resistencia ofrecido (...)"
} 
A partir do estudo jurisprudencial, percebe-se a dificuldade em analisar este princípio e da mesma forma quantificar e qualificar estas perdas e a vantagem militar, o que vai contra o entendimento do Direito Internacional dos Direitos Humanos de proteção a todas as pessoas sem discriminação de qualquer natureza, tal qual dispõe o artigo 1 da Convenção Americana de Direitos Humanos (OEA, 1969) ${ }^{5}$.

Recentemente, para falar do uso da força, a Corte apontou que a violência sexual é uma estratégia de controle, domínio e imposição de poder em contextos de conflito armado, utilizando os corpos femininos como ferramentas para transmitir sua mensagem de repressão e desaprovação aos meios de protesto utilizados pelos civis (CorteIDH, 2018, §202-204)

Por fim, o princípio da precaução (o mais utilizado para defesa estatal) diz respeito ao cuidado constante de preservação da população civil e aos bens de caráter civil, tomandose as devidas medidas para reduzir ao mínimo ou evitar o número de mortos e feridos decorrente de ataques militares, que sejam causados incidentalmente em face da vantagem militar concreta que será alcançada (HENKAERTS et al, 2007, Normas 15, 17 e 18). O princípio está previsto no artigo 57.1 do Protocolo Adicional I às Convenções de Genebra e, de forma implícita, no artigo 13.1 do Protocolo Adicional II às Convenções de Genebra.

A Base de Dados Direito Internacional Humanitário (ICRC, Capítulo 1) organizada pelo Comitê Internacional da Cruz Vermelha aponta nas regras 15, 22, 23 e 24 o princípio da precaução e estabelece que entre as medidas a serem adotadas, duas específicas: a localização dos objetivos militares fora de zonas densamente povoadas e a remoção dos civis (regra 23) e de objetos civis das proximidades dos objetivos militares (regra 24). Entre as medidas de precaução mais gerais elencadas na regra 22, tem-se a construção de abrigos, a realização de avisos, a designação da população para localidades seguras, direcionamento do trânsito, a proteção à propriedade civil, a mobilização civil e de organização de defesa.

Mais uma vez, no caso Cruz Sánchez e outros Vs. Peru, o Tribunal entendeu que, de fato, o operativo realizado pelo Estado teve como objetivo a retomada dos reféns com vida e que realizou um planejamento, a fim de minimizar o número de mortos e feridos, ponto o qual

\footnotetext{
5“Artigo 1. Obrigação de respeitar os direitos: 1. Os Estados Partes nesta Convenção comprometem-se a respeitar os direitos e liberdades nela reconhecidos e a garantir seu livre e pleno exercício a toda pessoa que esteja sujeita à sua jurisdição, sem discriminação alguma por motivo de raça, cor, sexo, idioma, religião, opiniões políticas ou de qualquer outra natureza, origem nacional ou social, posição econômica, nascimento ou qualquer outra condição social; 2. Para os efeitos desta Convenção, pessoa é todo ser humano."
} 
não foi questionado pela representação das vítimas ou pela CIDH (CorteIDH, 2015, §§284 e 285). No entanto, a CorteIDH entendeu que, no presente caso, a análise não deveria ser acerca do cumprimento de cada princípio, mas se o falecimento das três vítimas apresentadas decorreu da ação das forças policiais, uma vez que estes não estavam mais em combate (CorteIDH, 2015, §287) ${ }^{6}$.

\subsection{VULNERABILIDADE}

Nos casos relativos ao Direito Internacional Humanitário é ressaltado constantemente a vulnerabilidade da população civil e a dificuldade em determinar a pessoa combatente. Apesar da existência de alguns parâmetros para tal delimitação, não há como excluir totalmente a possibilidade de rendição, ou seja, como determinar se de fato houve rendição ou se consideram-se as possíveis mortes que decorreriam do ataque.

Sobre o assunto, o Relator Especial das Nações Unidas sobre Execuções Extrajudiciais, Sumárias e Arbitrárias afirma que existe a intenção de matar, quando há possibilidade de causar morte, na medida em que é uma decisão que descarta a possibilidade de oferecer ou aceitar a possibilidade de render-se (ONU, 2011, §§66 e 67).

Outro aspecto desta vulnerabilidade da população civil, é o próprio estado de medo e das condições sociais características dos conflitos armados. A CorteIDH ressalta a particular condição de vulnerabilidade do conflito armado interno, em especial o colombiano, elencando como obrigação dos Estados a adoção de todas as medidas necessárias e razoáveis para a garantia do direito à vida, liberdade pessoal e a integridade pessoal dos defensores e defensoras, que denunciam as violações de Direitos Humanos, principalmente em face de risco real e iminente (CorteIDH, 2009, §90).

O Tribunal afirma ainda que as condições adversas, como a pobreza e a própria existência do conflito armado pode proporcionar efeitos de magnitude maior do que causaria

\footnotetext{
6 "La Corte estima, por tanto, que la controversia no gira en torno a la necesidad, proporcionalidad y precaución en el uso de la fuerza (...), la controversia fáctica relevante, que indubitablemente tendrá efectos sobre el análisis jurídico en cuanto a una eventual violación al artículo 4 de la Convención Americana, se centra en determinar si (...) fallecieron como consecuencia de actos de agentes estatales una vez que se encontraban fuera de combate y, en consecuencia, podían calificarse como hors de combat en términos de derecho internacional humanitario o si, por el contrario, murieron cuando tomaban parte activa en las hostilidades (...)".
} 
àqueles que não estão submetidos às mesmas condições, caracterizando-as como mais vulneráveis (CorteIDH, 2012a, §273).

Em relação aos deslocados de proveniência rural, a CorteIDH sustenta que a vulnerabilidade é reforçada, pois afeta em especial mulheres, as quais representam mais da metade do número de deslocados internos, bem como jovens, crianças e idosos (CorteIDH, $2005, \S 175)$.

Sobre o tema, em voto separado do Juiz A. A. Cançado Trindade admite que em relação às violações graves e sistemáticas de Direitos Humanos e do DIH, estas chamam a atenção da comunidade internacional, pois lidam com vítimas mais vulneráveis e indefesas, em face da deformada estrutura do poder público e a utilização desta para a violação de Direitos Humanos, pois há uma tendência em considerar alguns valores como superiores (CorteIDH, 2003, §30). Este voto ocorreu em relação ao caso Myrna Mack Chang Vs. Guatemala (2003) em que, devido a sua atividade profissional, a vítima foi assassinada e os autores materiais e intelectuais não foram punidos, fato reconhecido pelo Estado da Guatemala.

A questão da vulnerabilidade alcança um grau especial no que diz respeito às crianças. É do entendimento do DIDH e do DIH, que as crianças possuem proteção especial, sendo estas protegidas pelo artigo 19 da CADH, pela Convenção das Nações Unidas sobre os Direitos das Crianças e os artigos 6, 37, 38 e 39 do Protocolo Adicional II às Convenções de Genebra. Ademais, os artigos 3 e 4 do Protocolo Adicional II atribuem às crianças um cuidado privilegiado, especialmente em relação à educação e à unidade familiar.

No caso Massacre de Mapiripán Vs. Colômbia, a CorteIDH ressaltou que é proibido o recrutamento de crianças até 15 anos em conflito armado (CorteIDH, 2005, §153). Ademais, o Tribunal afirmou que, em relação às crianças, os efeitos gerados em conflito armado são mais graves em face de sua vulnerabilidade. Esta afirmação decorre dos graves resultados dos conflitos armados na continuidade da vida destas crianças, vez que, por muitas vezes, estas tornam-se órfãs, bem como são vítimas dos deslocamentos internos e internacionais, o que ocasiona a violação de sua integridade física e psicológica (CorteIDH, 2005, §155). Esta especial vulnerabilidade é ressaltada pela Corte devido às crianças estarem menos preparadas para adaptar-se ou responder de forma mais efetiva à tal situação e são as que mais sofrem as consequências (CorteIDH, 2005, §156). Ainda acerca do recrutamento de crianças, a 
CorteIDH utilizou no caso Vargas Areco Vs. Paraguai do posicionamento da CIDH, a qual considerou que o recrutamento obrigatório em relação aos menores de 18 anos apresenta condições similares a escravidão e à servidão forçada (CorteIDH, 2000, p. 1620) e, que portanto, deveriam ser proibidas, em face das obrigações da Convenção n. 182 da Organização Internacional do trabalho (OIT), a qual entende da mesma forma que a CIDH acerca do recrutamento e determina que esta prática deve ser eliminada.

\subsection{DESLOCAMENTOS FORÇADOS INTERNOS E INTERNACIONAIS}

Outro ponto que se observa com regularidade nos casos envolvendo o DIH analisados pela CorteIDH é a ocorrência dos deslocamentos forçados, sejam eles internos ou internacionais. Tal fato decorre do contexto de tensão que é noticiado em conflitos armados.

De acordo com Agência das Nações Unidas para os Refugiados (ACNUR), atualmente o número de deslocados internos mundialmente é de aproximadamente 43.503,362 pessoas, do qual o país com maior número é a Colômbia (7.976.412), representando quase que a totalidade do número Latino Americano (8.295.002), em razão dos conflitos armados, conforme dados do último relatório Global Trends (UNHCR, 2019, p. 76).

No caso Massacre de Mapiripán Vs. Colômbia, a CorteIDH entendeu pertinente o disposto no artigo 17 do Protocolo Adicional II às Convenções de Genebra, o qual proíbe que um país ordene o deslocamento das pessoas que se encontram sob sua jurisdição por motivos relativos ao conflito, a não ser que seja a fim de garantir a segurança dos civis ou por motivo militar imperioso. Caso o deslocamento obrigatório ocorra, de acordo com o Protocolo, o país deverá garantir condições mínimas, satisfatórias, para que estas pessoas sejam realocadas (CorteIDH, 2005, §172).

O retorno dessas pessoas necessita também de um cuidado especial, para que seja realizado com segurança, pois percebe-se que entre as consequências da volta está a perda da propriedade, desemprego, mudança das condições de vida e aumento no número de doentes (CorteIDH, 2005, §175), como se observou no caso colombiano. A situação de desigualdade também é um fator decorrente do retorno ao local original, os Estados devem privar de realizar ações que possam aumentar essa desigualdade, resultando em discriminação, sendo sua obrigação adotar medidas positivas para proteção das pessoas que sofrem discriminação (CorteIDH, 2005, §178). 
Além disso, o Tribunal ressaltou que o deslocamento interno gera uma crise de segurança e torna os mais vulneráveis propensos ao recrutamento por grupos paramilitares, do narcotráfico e guerrilha, reforçando sua característica de vulnerabilidade (CorteIDH, 2005, $\S 175)$.

Quanto ao caso Irmãs Serrano Cruz Vs. El Salvador, a Corte analisou a situação de uma família que, durante seu deslocamento, acabaram por separar-se e não foi descoberto o paradeiro das duas filhas da família. Para a Corte, era dever do Estado de El Salvador garantir condições e oportunidades, para que a família reencontrasse as duas filhas. No entanto, não houve uma investigação efetiva, o último fato sobre o qual se tem notícia é de que membros do Exército teriam entregado as crianças aos integrantes da Cruz Vermelha, porém, por falta de investigação, o paradeiro não foi determinado.

Em voto, o Juiz Manuel E. Ventura Robles ressaltou que o artigo 4 do Protocolo Adicional II às Convenções de Genebra dispõe acerca da obrigação estatal em proporcionar o reencontro, bem como o artigo 39 da Convenção das Nações Unidas sobre Direitos das Crianças, o qual estabelece que é dever do Estado garantir a reparação física, psicológica e a reintegração social de toda a criança que seja vítima de abandono ou de conflito armado (CorteIDH, 2005, §§145 e 147).

Em casos mais recentes, como o Massacre de Ituango Vs. Colômbia e no Massacre de Santo Domingo Vs. Colômbia, a Corte passou a utilizar dos Princípios Reitores dos Deslocados Internos das Nações Unidas, para interpretar o alcance do artigo 22 da CADH, bem como do regulado no Protocolo Adicional II às Convenções de Genebra (CorteIDH, 2012a, $\$ 209$ e 256). O princípio reitor número 17, do qual a Corte se refere, afirma que todo ser humano tem direito a que se respeite a sua vida familiar e que todas as famílias separadas devido aos deslocamentos serão reunidas o mais rápido possível.

\subsection{O DIREITO À VIDA: UMA RELAÇÃO ENTRE A CONVENÇÃO AMERICANA DE DIREITOS HUMANOS E O ARTIGO 3 COMUM ÀS CONVENÇÕES DE GENEBRA}

O artigo 4 da Convenção Americana de Direitos Humanos dispõe que:

4.1. Toda pessoa tem o direito de que se respeite sua vida. Esse direito deve ser protegido pela lei e, em geral, desde o momento da concepção. Ninguém pode ser privado da vida arbitrariamente. (grifo nosso) 
Para a CorteIDH, o direito à vida tem um papel fundamental na Convenção, por ser essencial para a realização dos demais direitos (CorteIDH, 2004c, §153; 2003, §152), visto que ao se desrespeitar o direito à vida, todos os demais desaparecem, pois se extingue seu titular (CorteIDH, 2004b, §156). Destarte, o Estado tem a obrigação de criar condições para que as violações a esse direito não ocorram.

No caso Massacre El Mozote Vs. El Salvador, a Corte analisou as violações ocorridas de forma separada entre as pessoas que foram executadas, os sobreviventes diretos das atrocidades e os familiares dos executados. Logo, o Tribunal reafirmou as obrigações positivas e negativas em relação ao direito à vida daqueles que se encontram sob sua jurisdição, ressaltando que há um núcleo inderrogável de direitos, os quais não são passíveis de suspensão, conforme previsto no artigo 27.2 da CADH. Este núcleo inderrogável é composto pelo direito à integridade pessoal e o direito à vida (CorteIDH, 2012b, §§145 e 148), conforme decidiu a Corte e com o posicionamento assumido pelo Comitê Internacional da Cruz Vermelha em diversos documentos (ICRC, Capítulo 1; ICRC, 2010).

As Convenções de Genebra, por sua vez, protegem as pessoas que não participam de forma direta das hostilidades, nos quais deve-se incluir os que estão feridos e os que tenham depostos as armas, conforme dita o artigo 3 comum as 4 Convenções de Genebra. Da mesma forma entende o artigo 13.3 do Protocolo Adicional II às Convenções de Genebra, o qual afirma que os civis gozam da proteção atribuída, salvo se participarem de forma direta das hostilidades.

No entanto, no Direito Internacional Humanitário, os combatentes perdem os direitos comumente concedidos aos civis, então, poderia ocorrer uma privação não arbitrária da vida?

A CorteIDH entende como privação arbitrária da vida aquela que se utiliza de força ilegítima, excessiva e desproporcional (CorteIDH, 2011, §49; 2012d, §92). Em casos envolvendo o DIH, o entendimento firmado é que nem toda a privação do direito à vida será arbitrária (CorteIDH, 2015, §261). Para isso, o Tribunal sustenta que o uso excepcional da força letal deverá ser previsto em lei e ser interpretado de maneira a minimizar os efeitos, estando restrito ao "absolutamente necessário" com relação à ameaça que se pretende repelir (CorteIDH, 2015, §262; 2006, §68; 2007, §84).

A partir disso, pode-se observar que a Corte aderiu ao conceito da precaução do DIH aos seus posicionamentos. Para fundamentar esse pensamento, a Corte volta a utilizar os 
Princípios Básicos sobre o Emprego da Força e Armas de Fogo, reafirmando que devem ser respeitados os critérios do uso da força estabelecidos acerca da legalidade, proporcionalidade e absoluta necessidade explanados anteriormente neste artigo.

Além disso, no caso Cruz Sánchez e outros Vs. Peru, a CorteIDH ressalta seu posicionamento de que a CADH não define de maneira expressa o alcance da Corte acerca da aplicabilidade do conceito da privação arbitrária da vida, portanto, é pertinente recorrer ao corpus iuris do DIH para analisar as obrigações estatais em cada caso, com base ainda nos princípios da proporcionalidade, precaução e distinção (CorteIDH, 2015, §273). No mesmo sentido entende a CIDH, ao afirmar que a CADH não apresenta nenhuma norma que distinga as hipóteses de permissão legítima de morte do inimigo ou sua proibição, devendo utilizar a interpretação do artigo 3, comum às Convenções de Genebra, para dirimir a questão, em que caso o dispositivo não seja infringido, não será considerada violação ao artigo 4 (CIDH, 2000, $\S 29)$.

No entanto, ao analisar os julgados em que a CorteIDH debate este mérito, os Estados foram condenados, vez que não respeitaram o princípio da distinção e da proporcionalidade, como no caso Myrna Mack Chang Vs. Guatemala (2003), Massacre de Santo Domingo Vs. Colômbia (2012), Massacre de El Mozote Vs. El Salvador (2012) e no caso Cruz Sánchez e outros Vs. Peru (2015).

\section{CONSIDERAÇÕES FINAIS}

As decisões da CorteIDH desenvolveram um arcabouço jurisprudencial que reforça a ideia de convergência entre o Direito Internacional dos Direitos Humanos e o Direito Internacional Humanitário. Isso é fruto de um processo gradativo de aplicação de técnicas de interpretação, que permitiram a Corte Interamericana aliar regras de interpretação claramente autorizadas pela Convenção Americana de Direitos Humanos em seu artigo 29, princípios norteadores e dispositivos pertencentes a estrutura normativa alheia ao Sistema.

Tais questões restam muito claras, quando se analisa os casos envolvendo conflitos armados internos, onde se vislumbra a ampliação das regras de proteção, conduzidas pela interpretação das normas interamericanas, mas também, muito por influência de decisões judiciais advindas de outros tribunais e, principalmente, por documentos não pertencentes ao corpus juris do DIDH, mas do Direito Internacional, que seria o DIH. 
Essa ampliação da análise dos tratados internacionais, para além dos de Direitos Humanos, justifica-se porque, como já exposto tanto o DIH como o DIDH compartilham do mesmo objetivo: a proteção dos indivíduos. Por isso, os Estados devem respeitar, proteger e propiciar ao máximo o disfrute dos direitos consagrados na Convenção Americana de Direitos Humanos, mesmo em tempos de conflito.

Cumpre ressaltar que o uso do Direito Internacional Humanitário pela Corte Interamericana não tem por escopo declarar violados direitos pertencentes à documentos normativos humanitários. No entanto, conforme apresentado pela análise dos julgados, tais dispositivos são utilizados como reforço argumentativo, de forma a complementar o entendimento da Corte acerca do contexto em que as violações ocorrem ou mesmo ainda ampliar o conteúdo dos dispositivos da $\mathrm{CADH}$.

Nesse processo de interpretação para ampliação da proteção de direitos, os princípios do DIH, mostram-se meios importantes para aproximação entre os dois regimes do Direito Internacional em questão, para os julgados da Corte Interamericana envolvendo conflitos armados.

Por fim, verifica-se que embora a Corte Interamericana, conforme determina o artigo 62.3 da $\mathrm{CADH}$, tenha sua competência fixada para aplicação dos dispositivos contidos na Convenção Americana, fazendo uso dos demais tratados interamericanos, outras previsões normativas para além do Sistema Interamericano e do próprio corpus juris dos tratados de Direitos Humanos, vem sendo objeto de análise por parte da CorteIDH, em função da ausência normativa sobre certos temos no SIDH.

\section{REFERÊNCIAS}

ASSOCIAÇÃO MÉDICA MUNDIAL. Declaração de Genebra. 1948.

CANÇADO TRINDADE, Antônio Augusto; PEYTRIGNET, Gérard; RUIZ DE SANTIAGO, Jaime. As três vertentes da proteção internacional dos direitos da pessoa humana.

Direitos Humanos, Direito Humanitário, Direito dos Refugiados. Versão Digital. Disponível em http://www.icrc.org/por/resources/documents/misc/direitos-dapessoahumana.htm, Parte I. 22 de abril de 2004. Acesso em julho de 2017.

. Desafios e conquistas do Direito Internacional dos Direitos Humanos no início do Século XXI. In: Antônio Paulo Cachapuz de Medeiros (Org.). Desafios do Direito Internacional Contemporâneo. Brasília: Fundação Alexandre de Gusmão, 2007. 
CIDH. Caso Juan Carlos Abella Vs. Argentina. Mérito. Relatório de 18 de novembro de 1997.

CIDH. Informe Anual da Comissão Interamericana de Direitos Humanos 1999, Capítulo 6, Recomendação sobre a erradicação do recrutamento e a participação de crianças em conflitos armados, de 13 de abril de 2000.

Corte Internacional de Justiça. Opinião Consultiva de 08 de julho de 1996, sobre legalidade do uso de armas nucleares.

Corte Internacional de Justiça. Opinião Consultiva de 09 de julho de 2004, sobre as consequências legais para a construção do muro nos territórios ocupados da Palestina.

CorteIDH. Caso Bámaca Velásquez Vs. Guatemala. Mérito. Sentença de 25 de novembro de 2000a.

CorteIDH. Caso Cruz Sánchez e outros Vs. Peru. Mérito, Reparações e Custas. Sentença de 17 de abril de 2015.

CorteIDH. Caso de la Cruz Flores Vs. Peru. Mérito, reparações e custas. Sentença de 18 de novembro de 2004a.

CorteIDH. Familia Barrios Vs. Venezuela. Mérito, reparações e custas. Sentença de 24 de novembro de 2011.

CorteIDH. Caso Instituto de Reeducação do Menor Vs. Paraguai. Exceções preliminares, mérito, reparações e custas. Sentença de 02 de setembro de 2004 b.

CorteIDH. Caso Irmãs Serrano Cruz Vs. El Salvador. Exceções Preliminares. Sentença de 23 de novembro de 2004 c.

CorteIDH. Caso Las Palmeras Vs. Colômbia. Exceções preliminares. Sentença de 04 de fevereiro de $2000 \mathrm{~b}$.

CorteIDH. Caso Massacre de Mapiripán Vs. Colômbia. Mérito, reparações e custas. Sentença de 15 de setembro de 2005.

CorteIDH. Caso Massacre de Santo Domingo Vs. Colômbia. Exceções preliminares, mérito e reparações. Sentença de 30 de novembro de 2012a.

CorteIDH. Caso Massacres de EI Mozote e lugares próximos Vs. EI Salvador. Mérito, Reparações e Custas. Sentença de 25 de outubro de 2012b.

CorteIDH. Caso Montero Aranguren e outros (Retén de Catia) Vs. Venezuela. Mérito, reparações e custas. Sentença de 05 de julho de 2006. 
Corte IDH. Caso Mulheres Vítimas de Tortura Sexual em Atenco Vs. México. Exceção Preliminar, Mérito, Reparações e Custas. Sentença de 28 de novembro de 2018.

CorteIDH. Caso Myrna Mack Chang Vs. Guatemala. Mérito, reparações e custas. Sentença de 25 de novembro de 2003.

CorteIDH. Caso Nadege Dorzema e outros Vs. República Dominicana. Mérito, reparações e custas. Sentença de 24 de outubro de 2012c.

CorteIDH. Caso Pollo Rivera e outros Vs. Peru. Mérito, reparações e custas. Sentença de 21 de outubro de 2016.

CorteIDH. Caso Valle Jaramillo e outros Vs. Colombia. Mérito, reparações e custas. Sentença de 7 de julho de 2009.

CorteIDH. Caso Zambrano Velez e outros Vs. Equador. Mérito, Reparações e Custas. Sentença de 04 de julho de 2007.

EL KOUHENE, M. Les garanties fondamentales de la personne en droit humanitaires e droits de l’homme, 1986.

GIOIA, Andrea. The role of the European Court of Human Rights in Monitoring Compliance with Humanitarian Law in Armed Conflict. In BEN-NAFTALI, Orna. International

Humanitarian Law and International Human Rights Law. Oxford University Press, 2011, p.201-249.

HATHAWAY, OONA; SHAPIRO, SCOTT. The Internationalists: how a radical plan to outlaw war remade the world. PENGUIN BOOKS LTD. EDIÇÃO DO KINDLE, 2017

HENKAERTS, Jean-Marie; DOSWALD, Beck Louise. El Derecho Internacional Humanitario Consuetudinario. Norma 14, v I. Buenos Aires: CICR, 2007.

HIDAKA, Leonardo Jun Ferreira. Introdução ao Direito Internacional dos Direitos Humanos. São Paulo: Edições Loyola, 2002.

ICRC. Base de Dados do Direito Consuetudinário. Capítulo 1, regras 15, 22, 23 e 24. 2005. Disponível em: <https://ihl-databases.icrc.org/customary-ihl/eng/docs/home> Acesso em março 2021.

ICRC. DIH e Outros Regimes Legais: Jus in bello - Jus ad bellum. Disponível em <https://www.icrc.org/pt/guerra-e-o-direito/dih-e-outros-regimes-legais/jus-bello-jusadbellum>. Acesso em março de 2021.

ICRC. Guia para interpretar a noção de participação direta nas hostilidades segundo o Direito Internacional Humanitário. Dezembro de 2010. Disponível em < https://www.icrc.org/spa/assets/files/other/icrc_003_0990.pdf>. Acesso em março de 2021. 
KLEFFNER, Jann K. Human Rights in Armed Conflict. In: FLECK, Dieter (Ed.). The handbook of international humanitarian law. Oxford University Press, 4. Ed. 2021.

MÉGRET, Frédéric. Detention by Non-State Armed Groups in NIACs: IHL, International Human Rights Law and the Question of the Right Authority. In: HEFFES, Ezequiel; KOTLIK, Marcos; VENTURA, Manuel. International Humanitarian Law and Non-State Actors: Debates, Law and Practice, 2019, p. 169-194.

ONU. Código de conduta para funcionários encarregados de fazer cumprir a lei, aprovado pela Assembleia Geral das Nações Unidas em sua resolução 34/169. 17 de dezembro de 1979.

ONU. Comissão de Direito Internacional. Relatório de Trabalho, 58 sessão, UN Doc. A/61/10 de 2006, p. 409

ONU. Convenção sobre Munições Cluster. 01 de agosto de 2010.

ONU. Estatuto da Corte Internacional de Justiça. 26 de junho de 1945.

ONU. Informe do Relator Especial sobre Execuções extrajudiciais, sumárias ou arbitrárias. UN Doc. A/66/330. 30 de agosto de 2011.

ONU. Princípios básicos sobre o emprego da força e de das armas de fogo por funcionários encarregados de cumprir a lei. Adotados pelo Oitavo Congresso das Nações Unidas sobre Prevenção do Delito e Tratamento do Delinquente celebrado em La Habana, Cuba, do dia 27 de agosto ao dia 7 de setembro de 1990.

PIOVESAN, Flávia. Direitos Humanos e o Direito Constitucional Internacional. São Paulo: Saraiva, 2006.

TEDH. Caso Hassan Vs. Reino Unido. Sentença de 2014.

TEDH. Caso Korbely Vs. Hungria. Sentença de 19 de setembro de 2008.

UNESCO. Convenção para a Proteção de Bens em Caso de Conflito Armado. Haia, 1954.

UNHCR. Global Trends: Forced Displacement in 2019. 18 de junho de 2020. Disponível em:

<https://www.unhcr.org/5ee200e37/\#_ga=2.94798682.776429483.16173234541284684742.1 617323454>. Acesso em março de 2021. 